\title{
ENTEXTUALIZAÇÕES ESTRATÉGICAS: PERFORMANCES SENSUALIZADAS DE RAÇA EM PRÁTICAS DISCURSIVAS NA WEB 2.0
}

\author{
Thayse Figueira Guimarães* \\ Universidade Vale do Rio Verde \\ Três Corações, MG, Brasil \\ Luiz Paulo da Moita Lopes ${ }^{* *}$ \\ Universidade Federal do Rio de Janeiro \\ Faculdade de Letras \\ Departamento de Letras Anglo-germânicas \\ Rio de Janeiro, RJ, Brasil
}

\begin{abstract}
Resumo: Este artigo focaliza as práticas discursivas de Luan, um jovem negro e de identificações homoeróticas, em interação na Web 2.0. Os dados foram gerados em uma investigação etnográfica, no contexto interacional da rede social Facebook. As noções de entextualização e de performances são privilegiadas para dar conta da observação dos processos de circulação e desestabilização de discursos cristalizados de raça, na construção das identificações de Luan como garoto negro e sensual. Defende-se que tais noções são a chave de leitura para a compreensão de como tais discursos são estrategicamente utilizados pelo jovem, ao construir suas performances nas interações com amigos dessa rede social. As análises apontam que identificações de raça são entremeadas por marcas de gênero/sexualidade e que estratégias de agenciamento emergem em meio a uma profusão de significados normativos.
\end{abstract}

Palavras-chave: Performance identitária. Entextualização. Agenciamento.

\footnotetext{
* Professora do Programa de Mestrado em Letras. Doutora em Linguística Aplicada pela Universidade Federal do Rio de Janeiro. Agradeço ao CNPq pela bolsa 163647/2014-3, no âmbito do Edital MEC/CAPES e MCT/CNPq/FINEP No 28/2010 - Programa Nacional de Pós-Doutorado - PNPD 2010, que possibilitou este estudo. Tal bolsa foi concedida ao Projeto "Letramentos Digitais Singularidades do Ethos, Performances e Narrativas Identitárias", do Prof. Dr. Luiz Paulo da Moita Lopes (CNPq 560303/2010-06). E-mail: thayse.guimaraes@unincor.edu.br

** Professor Titular do Programa Interdisciplinar de Linguística Aplicada. Agradeço ao CNPq pela Bolsa de Produtividade que propiciou esta pesquisa (CNPq 3033-1/2009-0), assim como ao auxílio à pesquisa da FAPERJ (E -26/110.065/2012) e ao PNPD (MEC/CAPES e MCT/CNPq/FINEP) referido na nota anterior. Sou também grato ao CNPq pelo auxílio (470547/2012-0) concedido pelo Edital Universal (14-2012). Email: moitalopes@pq.cnpq.br.
} 
Luan, 22 anos, publicou o post abaixo, que lhe gerou algumas curtidas e comentários sobre suas identificações de gênero, sexualidade e raça, em sua rede social do Facebook ${ }^{1}$ :

\begin{abstract}
"o povo comenta no Facebook sobre minha vida, o povo gosta de falar. Pode falar. Eu sou o pretinho que incomoda, que faz a moda, o mais bonitinho da roda. Sei de uma coisa cara, se antigamente o negro sofria de preconceito hoje em dia negro sofre de assédio \#reflita."

[a este post, segue uma foto em preto e branco de Luan, focalizando sua boca e seu tronco nu] (Publicado em julho de 2012)
\end{abstract}

Seu post bem ilustra como sistemas de significação de gênero, sexualidade e raça se entrecortam em suas relações interacionais, nessa rede social. Na publicação, acima ilustrada, Luan se dirige a amigos virtualmente presentes e constrói sua participação na intersecção de demarcações de raça e de gênero/sexualidade pelas assertivas: "sou o pretinho que incomoda"; "hoje em dia negro sofre de assédio", seguida de uma foto em preto e branco, focalizando a boca e o tronco nu de Luan. O jovem faz uso de signos identitários que produzem efeitos de uma identificação específica. Em sua publicação, Luan é um garoto negro, sensual e desejado por seus amigos. Essa inter-relação está fortemente presente nas interações de Luan, caracterizando um dos aspectos do ethos ${ }^{2}$ (KERBRAT-ORECCHIONI, 1996) interacional que o jovem mobiliza nessa rede social. Ao promover seu corpo como desejável e belo, Luan é comentado e curtido por um grande número de pessoas. Essa valorização do corpo corresponde às expectativas próprias dos espaços on-line, em que há uma inclinação para valorização da aparência e da imagem do corpo como uma mercadoria em exposição (BAUMAN, 2011).

Ademais, pela profusão de recursos interacionais presentes nas interações on-line, as performances de Luan não estão necessariamente presas às identificações tradicionais. Elas podem ser (re)criadas por elementos multissemióticos, tais como fotos editadas, citações, emoticons, comentários de amigos/as e tantos outros recursos disponíveis no site e na própria rede. Tais recursos mobilizam discursos poderosos na articulação das hierarquias sociais e na negociação dos relacionamentos afetivo-sexuais e das performances identitárias de milhares de jovens na contemporaneidade. Para autores como Bauman (2011, p. 24), nesse mundo, a (re)construção das identificações está na ordem do dia, visto que o engajamento na produção de uma persona em contextos de interação on-line é parte do cotidiano de muita gente. Este é, sem dúvida, um modo de ser e agir que abre espaço para novas formas de relações sociais e de assimetrias, cujos efeitos precisam ser ainda dimensionados. Por esse viés, argumentamos que, no contexto

\footnotetext{
${ }^{1}$ Facebook é uma rede social lançada em 4 de fevereiro de 2004. Nesse website os usuários criam perfis que contêm fotos e listas de interesses pessoais, trocando mensagens privadas e públicas entre si e participantes de grupos de amigos.

${ }^{2}$ Neste artigo, usamos o conceito de ethos em associação à noção de ethos como hábitos locucionais compartilhados por membros de uma comunidade, conforme C. Kerbrat-Orecchioni (1996). Tal "ethos coletivo" constitui, para os locutores que o compartilham, um "perfil comunicativo", ou seja, a sua maneira de se comportar e de se apresentar nas interações (KERBRAT-ORECCHIONI, 1996).
} 
interacional da $\mathrm{Web} 2.0^{3}$, multiplicam-se as fronteiras e os atravessamentos identitários aparecem mais intensamente, constituindo os significados da vida corpórea atual.

Diante dessas questões, neste artigo propomos um olhar etnográfico acerca dos modos como fragmentos de discursos sobre gênero, sexualidade e raça são entextualizados (cf. BLOMMAERT, 2005; WOYDACK; RAMPTON, 2015), nas práticas interacionais de Luan, em interação com amigos no Facebook. Ou seja, como signos identitários circulam e são recontextualizados nos diferentes contextos interacionais em que Luan participa. Os dados são parte de um estudo etnográfico, que ocorreu ao longo de 12 meses $^{4}$. Serão focalizadas as lutas performativas encenadas entre Luan e os amigos, Moreira e Sávio, na negociação de sentidos válidos em suas práticas interacionais. Com base no questionamento sobre como Luan se reconhece como sujeito de uma raça, realizamos uma reflexão sobre o olhar que ele lança para sua corporalidade negra, observando aspectos de suas identificações de gênero e sexualidade. Importa aqui compreender como Luan recebe, responde e refuta, ou seja, como adere a esses signos identitários com determinados propósitos, ao se envolver em práticas comunicativas específicas. Defende-se que a repetição de signos estereotípicos de raça por meio das entextualizações é produtivamente utilizada por Luan a serviço de uma micropolítica de contestação dos lugares privilegiados, nas suas relações inter-raciais com seus amigos dessa rede social.

À luz do exposto, a primeira parte do artigo tratará da dimensão performativa da linguagem e versará sobre a dinâmica das entextualizações, ao discutirmos os processos de produção, circulação e recepção de discursos culturalmente sedimentados. Em seguida, discutem-se as identificações de gênero, sexualidade e raça como performances, trazendo para esta pauta a articulação necessária e crucial das formas das diferenças raciais e sexuais, como apontadas por Homi Bhabha (2007). Depois, apresentamos o contexto de pesquisa, a metodologia e as categorias teórico-analíticas para, finalmente, passarmos à análise. Tais referenciais evidenciam que é nas situações discursivas que construímos nossas identificações sociais. Nesse sentido, interessa-nos a produção de um conhecimento, no campo dos estudos da linguagem, que colabore na compreensão das situacionalidades discursivas das identificações de gênero, sexualidade e raça (MOITA LOPES, 2006/2014).

\section{A DIMENSÃO PERFORMATIVA DA LINGUAGEM E A DINÂMICA DAS ENTEXTUALIZAÇÕES}

A teoria da performance vem sendo apontada como uma alternativa às teorizações pautadas em uma perspectiva essencialista de linguagem. Segundo Bial (2003, p. 57), performance é um conceito útil na construção de conhecimentos sobre fenômenos sociais. Performance é prática/encenação. A repetição estilizada de atos corpóreo-

\footnotetext{
${ }^{3}$ Caracterizamos a Web 2.0 como um tipo de mindset, ou seja, um modo de pensar e conhecer o mundo vivido (LANKSHEAR e KNOBEL, 2008, p.31). Na Web 2.0, o mindset é orientado sob a lógica da participação, da colaboração e a da inteligência coletiva.

${ }^{4}$ Este artigo desenvolve parte da pesquisa etnográfica realizada por um dos pesquisadores (GUIMARÃES, 2014), dentro de um projeto que focalizava as performances corpóreo-discursivas de Luan, no contexto interacional da escola e das redes sociais virtuais. Na época, Luan era estudante do terceiro ano do ensino médio de uma escola pública, em uma cidade da região das Baixadas Litorâneas do Estado do Rio de Janeiro. Por motivos éticos, usamos pseudônimos para todos/as os/as participantes envolvidos/as.
} 
discursivos é uma realização performativa (COUPLAND, 2007). Crucial nos estudos das performances é o conceito de performativo desenvolvido por Austin (1962) no livro How to do things with words. Em suas conferências iniciais, Austin (1962/1990) propôs discutir os enunciados performativos. Em síntese, trata-se de enunciados que não poderiam ser avaliados como verdadeiros ou falsos, mas como felizes ou infelizes, tendo em vista seus efeitos no mundo. Nesse caso, como a verdade sempre foi central na filosofia, a problemática levantada por Austin é uma crítica a uma compreensão comum de que o discurso consistiria essencialmente em relatar/constatar/descrever o que é verdadeiro ou falso, o que Austin (1962, p. 3) chamou de "falácia descritiva" ou "pseudodeclaração".

Na visão de Schiffrin (1994), uma das principais preocupações de Austin consiste em determinar as condições ou, melhor dizendo, as pressuposições da realização do ato de fala total. A análise dessas pressuposições desenvolve-se na direção de uma tentativa de estabelecer as condições convencionais/formais (SCHIFFRIN, 1994), que deveriam ser satisfeitas para a realização bem-sucedida do ato de fala. Segundo Austin (1962/1990), para a "felicidade de um ato de fala", são necessárias algumas condições, incluindo nessas, enunciados ditos por pessoas adequadas, com certo pensamento ou sentimento e certa intenção de contuda. Por exemplo, para que um batismo seja realizado são necessárias condições adequadas para tal ato: como uma igreja, a batina do padre, certos procedimentos e a pessoa autorizada, que deve ter a intenção de realizar o batismo. Do contrário, o ato não terá nenhuma validade. $\mathrm{O}$ autor entende que, quando o proferimento não obedece às condições adequadas, ocorre um desacerto, e assim o ato de fala pretendido passa a ser sem efeito.

Derrida (1988), entretanto, na revisão dos conceitos de Austin, afirma que a questão fundamental acerca da performatividade da linguagem não se relaciona tanto ao atendimento das condições convencionais/formais que dão força a um ato de fala, mas sim ao caráter de repetição e citação próprio da linguagem em uso. Para o autor (DERRIDA, 1988), uma característica de toda comunicação, escrita ou falada, é sua iterabilidade e citacionalidade, ou seja, a possibilidade de ela ser repetida, citada e transmitida por um terceiro e depois por outros. Derrida (1988) caracteriza a linguagem como constituída pela iterabilidade, ao dizer que "a possibilidade de repetir e, pois, de identificar as marcas está implicada em todo código, faz deste uma grade comunicável, transmissível, decifrável, iterável por um terceiro, depois para todo usuário possível em geral” (DERRIDA, 1988, p. 19). É exatamente a possibilidade de repetição de um fragmento de linguagem em diferentes circunstâncias que torna possível o performativo. O interesse de Derrida estaria, diferentemente de Austin, em identificar não o que possibilita o êxito ou não de enunciados performativos, mas o "modo pelo qual o uso da linguagem tornou-se efetivo por repetição e citação” (PENNYCOOK, 2007, p. 67).

Assim, na visão derrideana (1988), os enunciados são performativos porque resgatam outros enunciados iteráveis, ou seja, enunciados que se conformam às regras de uso, sendo transportados e reatualizados nos contextos da interação. É necessário que os significados sejam iteráveis para que possam ser reconhecidos como fórmulas regulares que orientam a realização de determinados atos, em circunstâncias sérias ou não. Nesse caso, Derrida (1988) focaliza o fato de que nosso sistema linguístico é baseado em repetições - repetições que criam uma ideia de estabilidade do significado - sem a qual tal sistema não existiria. 
Ainda, de acordo com esse autor (DERRIDA, 1988), um texto não pode ser idêntico a si mesmo ou autossuficiente, isso porque com o tempo não poderíamos identificar o centro ou origem das repetições. Em razão disso, um signo linguístico nunca será idêntico a si próprio, visto que a própria iterabilidade que constitui sua identidade não lhe permite ser uma unidade de identidade consigo mesmo, sob pena de deixar de ser um signo (LOXLEY, 2007). Essa diferença é crucial para a produção de sentido e, ao mesmo tempo, assegura que o significado nunca é simplesmente mimético e transparente. Nesses termos, mesmo a citação, por mais fiel e contextualizada que se pretenda, altera aquilo que pretende apenas reproduzir (PENNYCOOK, 2007). Assim, a citação implicaria interpretações e não somente a transposição de sentidos fiéis a um texto original. Nesse caso, o que irá constituir qualquer ato de fala é justamente essa relação entre identidade e diferença, repetição e alteração, que constitui qualquer sistema ou código e que só é possível devido à ausência, ao fato de que o signo não carrega em si uma presença pura (DERRIDA, 1988). E é essa imbricação - repetição/diferença e replicação/transformação - que permite a performatividade, a principal condição que torna as performances linguísticas possíveis, a condição que possibilita o sucesso dos enunciados (PENNYCOOK, 2007). A força da linguagem aparece aí relacionada à repetição e à relocalização, que sempre produz algo novo, perpassado de um sentido de tempo/movimento, em contextos diversos e com novos arranjos.

Essa abordagem pode encontrar ecos em algumas vertentes da sociolinguística (BLOMMAERT, 2005; BLOMMAERT; RAMPTON, 2011; WOYDACK; RAMPTON, 2015) e da antropologia linguística (AGHA, 2007; SILVERSTEIN; URBAN, 1996; BAUMAN; BRIGGS, 1990), quando refletem sobre os processos de contextualização dos fenômenos sociolinguísticos na contemporaneidade. Nessa perspectiva, textos e discursos são compreendidos como "projéteis transportáveis que viajam através dos contextos" (WOYDACK; RAMPTON, 2015, p. 4), passando por sucessivos processos de entextualização. A entextualização refere-se "ao processo de tornar o discurso passível de extração, de transformar um trecho de produção linguística em uma unidade - um texto - que pode ser extraído de seu cenário interacional” (BAUMAN; BRIGGS, 1990, p. 73). Em termos gerais, o termo chama atenção para a característica fundamental dos textos e discursos de se descontextualizarem. Ou seja, de serem retirados de um contexto e replicados em outro, tornando-se um novo texto para além do seu contexto original, com novas condições para contextualização (WOYDACK; RAMPTON, 2015). Compreender o enunciado, assim, ajuda a entender que os discursos sobre gênero, sexualidade e raça em circulação pelo Facebook de Luan estabelecem conectividade com outros eventos comunicativos temporal e espacialmente diferentes. Entextualização, assim, sublinha o fato de que discursos sedimentados na cultura são utilizados, reutilizados, perpetuados e modificados na organização/constituição das práticas sociais, o que está em concordância com a eficácia produtiva da performance a partir da sua iterabilidade essencial.

Em diálogo com a dimensão performativa da linguagem, o fenômeno da entextualização sinaliza que, na repetição de discursos sedimentados na cultura, sentidos inéditos nascem, visto que, ao realocar tais discursos, sempre o fazemos de forma diferente. Isso porque a replicação sempre envolve um conjunto de transformações (BLOMMAERT, 2005). Ao serem recontextualizados, como afirma Woydack e Rampton (2015), os textos são construídos, adaptados e modificados pelos seus receptores. Assim, um texto entextualizado é a viagem que um discurso faz ao ser retirado de um lugar e 
recontextualizado em outro, tornando-se um novo texto. Em razão disso, Bauman e Briggs (1990, p. 74) afirmam que, para entendermos como os textos socioculturalmente construídos são (re)utilizados em nossas práticas discursivas diárias, devemos considerar "o que acontece com um texto uma vez que este é descontextualizado".

Tais dimensões ajudam-nos a visualizar o trajeto pluridirecional da construção dos sentidos na análise das performances de Luan, dando conta principalmente do circuito constante de contextualização, descontextualização e recontextualização de significados (BLOMMAERT, 2005). Tal abordagem enfatiza a fricção entre repetição e criatividade, mesmidade e novidade, próprios à dimensão performativa da linguagem e que promove a integração entre significados locais e sociohistóricos. Isso posto, passamos, na próxima seção, a considerar as questões levantadas por Judith Butler (2003, 2004a) sobre a materialidade corpórea pela performatividade, buscando apresentar novos argumentos à força constitutiva do discurso pelo princípio da iterabilidade.

\section{GÊNERO, SEXUALIDADE E RAÇA COMO PERFORMANCE}

São precisamente as questões apontadas anteriormente que importam para Judith Butler (1993, 2004 a, 2004 b), ao pensar em propor uma teoria performativa do gênero e da sexualidade. Butler problematiza a constituição dos sujeitos sociais pelas performances, ao estender a eficácia performativa dos atos de fala aos atos corporais (OLIVEIRA, 2010). Sua proposta é desnaturalizar a diferença sexual, ao observar como gênero e sexo são constituídos pelos usos do corpo (PRECIADO, 2010). Para Butler (2004a), as pessoas repetem atos performativos de gênero "masculino" e "feminino" e sua eficácia performativa impede identificarmos o ponto de origem dessas identidades. Isso porque, dado o caráter repetitivo e citacional da linguagem, como discutido anteriormente, os próprios termos, segundo a autora, através dos quais nos fazemos inteligíveis para nós e para os outros, não são criados por nós (BUTLER, 2004a). Repetimos e copiamos as cópias, porém, não há um original do gênero, porque o gênero é uma construção que escamoteia sua própria gênese (BUTLER, 2003, p.157).

Butler põe em pauta os processos pelos quais os corpos se tornam inteligíveis e são naturalizados dentro de uma ordem heteronormativa. Para a autora, os processos formativos da vida humana, isto é, do sujeito e do seu corpo, que constituem com ele sua capacidade de fala e sua legalidade social, são efeitos de práticas discursivas cotidianas sedimentadas, cuja força vem da sua iteração mesma, do seu caráter de citação (BUTLER, 1993). Dessa perspectiva, cada vez que os indivíduos agem discursivamente, significados estão em construção e novos modos de identificação podem ser encenados como performatividades que se constituem por meio de tomadas de agência, porque os indivíduos não estão simplesmente representando os jogos de linguagem prontos. Essa variação pode instaurar uma nova configuração identitária, um reposicionamento. Essa é uma abordagem que sustenta a noção de performatividade na qual estamos interessados. Performatividade como uma repetição que subverte a performance esperada e naturalizada (BUTLER, 2003). Nesse sentido, mesmo que a performance esteja associada a construções naturalizadas e repetidas, a sua performatividade (ou seja, suas condições de possibilidade) nunca é a mesma. 
Nessa linha de argumentação, essa noção de performance tem implicações importantes para a compreensão não só das identificações de gênero e sexualidade, como também para o entendimento sobre a forma pela qual as subjetividades são racializadas (COSTA DE PAULA, 2010). A raça, assim como a sexualidade, surge como conceito classificatório entre os séculos XVII e XVIII. Relacionada à natureza dos corpos, a raça foi definida como grandes divisões da humanidade, com base em certas características físicas e comportamentais em comum (SULLIVAN, 2003). De acordo com D’Adesky (2001, p.133), práticas racistas, baseadas na crença das diferenças raciais, colocaram muitos indivíduos em posições subalternas nas diversas partes do mundo. Mesmo na contemporaneidade, a discriminação racial, o padrão de beleza anglo-saxão, condições político-econômicas desiguais, a veiculação de imagens estereotipadas sobre a África permanecem vigentes (GUERREIRO, 2010).

Em concordância com Guimarães (2003) e Costa de Paula (2010), entendemos que raças (como gênero e sexualidade) são discursos sobre origens de um grupo que se atualizam nas práticas sociais, quando as pessoas são definidas em termos de traços fisionômicos, qualidades morais, intelectuais, fisiológicas etc. Esses processos de materialização do corpo negro acontecem mediante práticas insistentes de significação (estereótipos, declarações, piadas e mitos racistas) que desenham o campo mesmo do inteligível. Raça, assim, é um efeito de sentido, ou seja, um conceito que atua pelos discursos cristalizados de raça, na circunscrição de indivíduos e seus corpos em modos de vida geralmente estereotipados e racistas (BHABHA, 2007).

A esse respeito, Bhabha (2007) assevera que uma das principais estratégias do discurso do colonialismo na construção de subjetividades racializadas dá-se pelo discurso do estereótipo. Para este autor o "estereótipo" é um modo de representação paradoxal: "que vacila entre o que está sempre no lugar, já conhecido, e algo que deve ser ansiosamente repetido [...] como se não pudesse na verdade ser provado jamais no discurso" (BHABHA, 2007, p. 105). Deve-se compreender também a noção de raça em associação à performatividade, como uma repetição que subverte a performance esperada/naturalizada (BUTLER, 2003). Nesse sentido, mesmo a performance repetida (discutida aqui em relação à noção de estereótipo) compõe a diferença, que possibilita a mudança e transgressão dos limites das fronteiras do discurso colonial, uma vez que não há um original na questão da identificação, apenas citação de outras citações, que no decorrer do tempo ganham naturalidade e força enunciativa. Assim, a teorização butleriana sobre materialidade corpórea pelas performances abre possibilidade de abandono de sentidos calcificados também sobre raça, principalmente aqueles que constroem os negros como possuindo uma identidade racial definida e essencializada, para além das suas peculiaridades históricas, sociais e locais (cf. COSTA DE PAULA, 2010).

Com base nos argumentos apresentados, entende-se que a raça também é a materialização de um discurso performativo, que não se desassocia da materialização de gênero e sexualidade. Por isso vários teóricos têm frisado a importância de estudar as relações e intersecções de gênero, sexualidade e raça (BARNARD, 2004; SULLIVAN, 2003). Essa é uma proposta que comparece nas Teorias Queer (BARNARD, 2004; SULLIVAN, 2003; SOMMERVILLE, 2000), em que a questão não é ter em conta a 
especificidade racial ou étnica da opressão como mais uma variante junto à opressão sexual ou de gênero, mas analisar a constituição mútua do gênero e da raça, o que é compreendido como "a sexualização da raça e a racialização do sexo" (PRECIADO, 2010, p. 52).

A sexualidade é racialmente marcada, assim também como a marcação da raça é impregnada de sexualidades específicas (BARNARD, 2004). Como destaca Anzaldúa (1991, p. 252-253), ao criticar o modelo aditivo de identidade, "a identidade não é um amontoado de cubículos estufados respectivamente com intelecto, sexo, raça, classe, vocação, gênero. Identidade flui entre, sobre, aspectos de cada pessoa. Identidade é um [...] processo". Isso porque, de acordo com Sullivan (2003, p. 72), ser posicionado como um homem homossexual negro é significativamente diferente de ser posicionado como homem heterossexual negro ou como homem branco homossexual. Nesse caso, não simplesmente porque um homem que se identifica como negro e gay sofre opressões isoladas com base na diferença de raça e sexualidade, mas porque a própria experiência de gênero/sexualidade, por exemplo, em cada um dos casos acima citado, é significativamente diferente (SULLIVAN, 2003). Assim, de acordo com Barnard (2004), ser posicionado ou se identificar como homem gay negro pode ser uma performance identitária em si e não uma combinação de performance identitária de negritude e uma performance identitária de homossexual. Essa é uma questão importante para se pensar nas performances de gênero/sexualidade e raça de Luan: um garoto negro que se posiciona como gay nas suas redes sociais on-line.

Assim, neste artigo, ao se propor o foco investigativo nas práticas discursivas de Luan, estamos interessados nas normatizações e no modo como Luan resiste, fazendo incorporações desviantes ou citações descontextualizadas de discursos cristalizados de gênero, sexualidade e raça a serviço de uma micropolítica de contestação dos lugares privilegiados, nas suas relações inter-raciais com seus amigos da rede social Facebook. Como discutido, essas repetições podem ser observadas por meio dos processos de entextualização de discursos (BLOMMAERT, 2005), ao focalizarmos como esses signos identitários são recebidos, incorporados, refutados, mantidos e alterados por sujeitos com expectativas interpretativas distintas e repertórios linguísticos específicos. Tal abordagem sublinha o fato que os processos comunicativos, centrais na ação humana em performance, envolvem uma infinidade de recursos semióticos amalgamados (linguísticos e não linguísticos) que são utilizados, reutilizados, perpetuados e modificados na construção das performances identitárias.

\section{CONTEXTO, METODOLOGIA DE PESQUISA E AS CATEGORIAS TEÓRICO-ANALÍTICAS}

Os dados apresentados aqui foram gerados na rede social do Facebook de Luan ${ }^{5}$. Os dados são parte de uma pesquisa etnográfica maior que envolveu um grupo de jovens, estudantes do ensino médio em uma escola pública das Baixadas Litorâneas do Estado do

\footnotetext{
${ }^{5}$ Por um compromisso ético de pesquisa, buscamos preservar o anonimato de Luan, sujeito focal, e de seus amigos on-line.
} 
Rio de Janeiro e que levou em conta a observação etnográfica no contexto da escola e dos espaços virtuais. A proposta da presente pesquisa focalizou as performances identitárias de Luan, o participante focal, na experiência de participação nas redes sociais on-line e nos eventos escolares. Considerando o caráter etnográfico ${ }^{6}$ desta pesquisa, no ano de 2011, um dos pesquisadores se inseriu, com consentimento de Luan, como participante de sua rede social, na qualidade de pesquisador, durante 12 meses. Tivemos acesso livre e consentido aos seus dados de Internet. Na observação das interações de Luan em suas redes sociais, foi possível notar que um tipo de ethos interacional de pessoa sensualizada comparecia constantemente em suas práticas discursivas. Em vários momentos, pode-se observar Luan mobilizando esse ethos por meio de fotos que expunham seu corpo semivestido, com legendas tais como: "sensualizando na rede", "vamos seduzir", "hoje eu estou o doce", "quer prazer, meu nome é Luan", entre outras (GUIMARÃES, 2014).

Nessa exploração etnográfica, chamaram-nos atenção as interpelações feitas a esse ethos interacional, principalmente aquelas produzidas por seus amigos Moreira e Sávio. Moreira e Sávio são amigos de Luan no Facebook ${ }^{7}$. Esses jovens eram vistos com frequência entextualizando discursos cristalizados de raça para comentar as postagens efetuadas por Luan. Neste artigo, exploraremos dois momentos interacionais em que Luan negocia sentidos válidos, com esses jovens, na intersecção de demarcações de gênero, sexualidade e raça.

Para a análise dessas práticas discursivas, além dos processos de entextualização, serão contempladas as categorias pistas de contextualização (1982/2002) e de footing (GOFFMAN, 1974 e 1981). As pistas de contextualização (GUMPERZ, 1982/2002) ${ }^{8}$ são, em termos mais amplos, todos os signos verbais e não verbais que permitem a sinalização contextual, e através das quais os/as interactantes podem compreender que atividade está ocorrendo, uma vez que os contextos não são dados (GUMPERZ, 1982/2002). As pistas de contextualização são pistas de natureza sociolinguística que utilizamos na sinalização de nossas ações comunicativas ou para inferir as predicações conversacionais dos interlocutores (RIBEIRO; GARCEZ, 2002). Nesse caso, quaisquer traços da forma linguística e/ou não linguística (por exemplo, os gestos, posturas etc.), que contribuam para assinalar as pressuposições contextuais, podem ter funções de contextualização.

\footnotetext{
${ }^{6}$ Abalizados pela proposta de Erickson (1984, p. 51), utiliza-se o termo pesquisa etnográfica para se referir a uma abordagem metodológica que privilegia a observação participante, com interesses atinentes à vida social, e por constituir "um processo deliberado de investigação guiado por um ponto de vista". Defendese ainda que as redes sociais virtuais são novos nichos de observação das práticas sociais, que impõem a pesquisadores das ciências sociais e humanas desafios quanto aos domínios de suas pesquisas (HINE, 2000).

7 Obtivemos também anuência de tais jovens para o uso de suas interações com Luan pelo Facebook.

${ }^{8} \mathrm{Na}$ análise realizada, destacam-se as pistas referência, predicação e citação, como apresentadas e discutidas por Wortham (2001, p.72). A referência diz respeito à nomeação das coisas e das pessoas e a predicação são os atributos conferidos na nomeação dessas pessoas e do mundo. Já a citação é a apropriação direta ou por ação de paráfrases do discurso de outro. Apesar de não nos aprofundarmos nas considerações feitas por Wortham (2001) e de não utilizarmos sua lista de pistas em sua totalidade, como instrumental analítico, recorreremos à metalinguagem, acima ilustrada, por considerarmos útil à nomeação das pistas de contextualização nesta análise.
} 
Gumperz (1982/2002), ao empreender a análise das interações face a face, listou um conjunto de pistas com função de contextualização. Entre outras estão: mudança de código, prosódia, escolhas lexicais e sintáticas, escolhas paralinguísticas etc. Ancorados nos estudos realizados por esse autor, compreendemos que as pistas de contextualização apresentam potencial teórico-analítico para interpretação das interações on-line. Entretanto, em decorrência da especificidade do contexto desta pesquisa (a rede social do Facebook), como aponta Wittel (2000), algumas das pistas típicas dos encontros face a face não estão acessíveis no espaço virtual e outros elementos precisam ser considerados. Em destaque, o uso de emoticons (figuras gráficas como corações ou carinhas tristes/alegres, entre outras, que geralmente expressam algum tipo de emoção), hashtag (é uma palavra ou frase prefixada pelo sinal \#, para formar um rótulo ou uma etiqueta), pontuações expressivas, letras maiúsculas, letras coloridas, entre outras. Trata-se de uma lista que não se esgota, tendo em vista todos os recursos semióticos que os interlocutores podem mobilizar nessas interações.

Argumentamos ainda, em diálogo com Collins (2011), que as pistas de contextualização de Gumperz (1982/2002), tão focadas nos contextos microinteracionais, podem ter importância fulcral para se investigar fenômenos macrossociológicos. Segundo Collins (2011), as pistas de contextualização agregam contribuições a trabalhos interessados nos processos de significação que vão além dos limites das interações localmente situadas, dando conta da natureza estratificada e laminada dos signos indexicais ${ }^{9}$. Dessa forma, defenderemos que tal construto realça a complexidade dos processos interacionais, em que escolhas lexicais, gramaticais, fonológicas, entonacionais, qualidade de voz, alinhamento, intertextos etc, ou seja, as escolhas linguísticas, paralinguísticas e discursivas estão em inter-relação com significados sóciohistoricamente fixados.

Sob esse aspecto, tais pistas de contextualização (GUMPERZ, 1982/2002) são fundamentais na compreensão dos footings projetados por Luan e por seus amigos. $\mathrm{O}$ "Footing representa o alinhamento, a postura, a posição, a projeção do eu de um participante na sua relação com o outro, consigo próprio e com o discurso em construção" (RIBEIRO; GARCEZ, 2002, p.107). O footing caracteriza, assim, a relação entre os participantes numa dada interação (GOFFMAN, 1981). Uma mudança de footing ocorre quando o alinhamento, postura, posição ou o eu projetado do participante está de alguma forma em questão. Em outras palavras, os interlocutores se realinham na conversa quando sentem necessidade de reajustar seu status de participação.

Por fim, concluímos que a observação do conjunto de footings projetados e das entextualizações de discursos referentes à raça, ao gênero e à sexualidade, culturalmente sedimentados, podem viabilizar a análise das lutas performativas encenadas entre Luan e seus amigos, na negociação de sentidos válidos em suas práticas interacionais. Como

\footnotetext{
9 A indexicalidade, segundo Silverstein (2003), é a propriedade do signo linguístico de apontar para projeções semiótico-textuais, que assinalam a interpretação de um ato comunicativo ao ser local e culturalmente contextualizado. Para esse autor, trata-se de um "conceito necessário para nos mostrar como relacionar o microssocial às análises dos enquadres macrossociais em qualquer fenômeno sociolinguístico" (SILVERSTEIN, 2003, p. 193). Uma análise indexical, assim, pressupõe laminações indexicais, ao se considerar sentidos que emergem nos contextos microinteracionais em imbricação com escalas mais amplas, onde regularidades macrossociais são saturadas ideologicamente (SILVERSTEIN, 2003).
} 
afirma Trester (2012), a entextualização demanda dos interlocutores, envolvidos no jogo interacional, reconhecimento dos textos que circulam e dos alinhamentos sugeridos. Nessas relações interacionais, aspectos de poder e assimetrias entre participantes (SILVERSTEIN; URBAN, 1996) vão ensejar lutas para fixar sentidos legítimos e impactar diretamente o modo como os recursos semióticos mobilizados serão recontextualizados.

\section{ANÁLISE DAS ENTEXTUALIZAÇÕES: PERFORMANCES SENSUALIZADAS DE RAÇA NAS PRÁTICAS DISCURSIVAS DE LUAN}

A seguir, discutem-se duas cenas que apresentam interações de Luan com seus amigos do Facebook, nas quais se destacam, no conjunto de dados, as intersecções de raça, gênero e sexualidade. As transcrições mostram Luan encenando performances identitárias em negociação coletiva com significados que constroem performances entrelaçadas de gênero/sexualidade e raça. Na primeira cena, focalizam-se as interações de Luan com Moreira, que, de acordo com nossas observações etnográficas, posiciona-se como um garoto branco e gay, nesse contexto interacional. A cena inicia-se com uma postagem de Luan, realizada no dia 2 de abril de 2011.

\subsection{A INTERAÇÃO COM MOREIRA}

\begin{tabular}{lll}
\multicolumn{1}{l}{$\begin{array}{l}\text { Post } \\
1\end{array}$} & Luan & Cheguei numa fase da vida onde não sinto mais necessidade de tentar \\
2 & & impressionar ninguém. Se gostarem do jeito que sou, ótimo \\
3 & & senão, dane-se! Bom dia pra quem é sensual! [ 12 curtir] \\
4 & & [foto selfie $^{10}$ de Luan sem camisa, olhando-se no espelho do banheiro] \\
5 & Thiago & Só para os corajosos.... Lindeza \\
6 & Sabrina & Concordo! Nego gato te amo muito! [1 curtir] \\
7 & Moreira & To falando q eh africano. Nem com fotoshop você fica bonito. \\
8 & & Desiste da vida. Chore na minha beleza alemã! Kkkkkkk \\
9 & Fábio & Kkkkkkkkk \\
1 & & Taaaa bom. Você vai querer se fazer pra cima de mim?! JAMAIS QUERIDO! \\
0 & Luan & Vc se \\
1 & & faz de sensual nas fotos.. mas eu sei que é zé ninguém na vida social. Você é \\
1 & & uma \\
1 & & lagartixa alemã. \#frangão \#magrelo \#feio \#érecalque. Chorem minha beleza \\
2 & & africana \\
1 & & Eu sou dotado X dotado. [emoticon piscadela] \\
3 & &
\end{tabular}

\footnotetext{
${ }^{10} \mathrm{~A}$ palavra é uma referência a um tipo de autorretrato, feita com uma câmera digital de mão ou celular com câmera.
} 
5 Fábio Isso é pra quem pode. [emoticon sorrindo]

O post de Luan apresenta elementos multissemióticos, que vão construir suas performances identitárias nessa rede social. Aqui, os elementos multissemióticos: foto selfie e a enunciação "Bom dia pra quem é sensual", combinam-se na projeção de um footing de pessoa sensual, caracterizando um dos aspectos do ethos (KERBRATORECCHIONI, 1996) que Luan mobiliza nessa rede social. Nessa interação, tais recursos alinham-se na construção de uma performance de garoto negro sensual e serão analisados quanto ao modo como são recontextualizados nos comentários de seu amigo Moreira.

Nas linhas 7 e 8, o comentário de Moreira relocaliza Luan, justapondo identificações sociais de gênero, sexualidade e raça. Por ação da referência "africano" (1.7), seguida da oração "Nem com fotoshop você fica bonito"(1.7), Moreira constrói as performances de raça de Luan como associadas ao não belo. Tais pistas parecem reciclar negativamente as performances de Luan e estão relacionadas a sentidos socialmente estabelecidos por uma matriz de inteligibilidade da raça, que estabelece para sujeitos sociais negros posições estigmatizadas que desqualificam esteticamente seus corpos. $\mathrm{Na}$ publicação seguinte, o interactante também se encaixa em um footing de superioridade ao enunciar "Chore na minha beleza alemã" (1.8). Sua identificação pela referência predicada "beleza alemã" faz circular discursos identitários socialmente construídos que conferem às pessoas brancas e de origem europeia maior prestígio que aquelas que se identificam como não brancas. Ao efetuar tais entextualizações, Moreira encena performativamente identificações de garoto branco e projeta footings em paralelo: o eu superior às performances de Luan é também um eu jocoso, que mobiliza discursos estigmatizados. A postagem de Moreira está em ação na construção das relações afetivo-sexuais desses jovens, sugerindo que a corporalidade negra de Luan não agrada a Moreira sexualmente.

Em resposta ao comentário de Moreira, Luan projeta um footing de oposição pela assertiva "Taaaa bom. Você vai querer se fazer pra cima de mim?! JAMAIS QUERIDO" (1.10). Os termos, em caixa alta, indicam entonação mais forte e podem ser avaliados como índice da construção de uma situação de embate entre Luan e Moreira, em que relações assimétricas estão em jogo na construção de suas performances nesse contexto interacional. No mesmo post, Luan projeta também um footing de ironia com a exclamativa "Vc se faz de sensual nas fotos.. mas eu sei que é zé ninguém na vida social" (1. 10 e 11). Nessa assertiva, Luan entextualiza um discurso do senso comum que enuncia a oposição entre o que é o virtual e o real. Seu texto projeta uma identificação para Moreira, cujas características físicas do virtual, sinalizadas pela assertiva "faz de sensual nas fotos" (1. 11), contrapõe-se à realidade, apresentada pelas referências e predicações enunciadas por Luan: "lagartixa alemã", "\#frangão", "\#magrelo" e " \#feio" (1.12). Desse modo, Luan posiciona Moreira fora dos padrões de força, próprios das chamadas masculinidades hegemônicas ${ }^{11}$ (cf. CONNELL; MESSRSCHMIDT, 2013), ao mesmo

11 A masculinidade hegemônica, segundo Connell e Messrchmidt (2013), distingue-se de outras masculinidades, principalmente das chamadas masculinidades subordinadas. Para tais autores a masculinidade hegemônica "incorpora a forma mais honrada de ser um homem, ela exige que todos os 
tempo em que constrói as performances do amigo como associadas ao não belo. Além disso, ao usar a etiqueta exclamativa "\#érecalque", Luan entextualiza um discurso circulante na cultura popular, frequentemente utilizado para significar inveja, e, nesse contexto interacional, parece produzir, conjuntamente com os demais itens lexicais, um alinhamento confrontacional com relação ao comentário do amigo Moreira.

Em seguida, Luan recria a provocação formada no comentário de Moreira e reivindica a valorização de suas performances em associação à referência predicada "beleza africana" (1.12) e pela predicação "dotado X dotado" (1.13), ao se construir performativamente como um garoto negro, sensual, belo, interessado em homens e que, ao contrário de Moreira, é bem dotado. Essas pistas indexam significados sobre o que Luan crê que sejam atributos identitários que valorizam suas performances de gênero, sexualidade e raça, nessa interação. Valoração compatível com um discurso cristalizado de raça, em que se assenta o ideal de homem negro como aquele que possui um grande pênis. As escolhas lexicais posicionam Luan como um homem que se enquadra nos padrões das masculinidades idealizadas quanto ao quesito sexualidade, visto que a fórmula "dotado X dotado", típica de chats gays, seguida do emoticon piscadela (1.13) projeta um footing avaliativo da parte de Luan sobre seu desejo e desempenho sexual, de modo a ser visto como atraente e desejado por outros homens.

Destaque-se, aqui, que, no jogo de construção de suas performances sensualizadas, a união dessas pistas parece reforçar um alinhamento de contestação a discursos racializados que inferiorizam suas performances, nesse contexto interacional. Em outras palavras, Luan entextualiza estrategicamente discursos cristalizados de raça e os adapta ao propósito de contestar os footings projetados por Moreira. Com o apoio de tais entextualizações, Luan opera uma inversão das assimetrias, em um movimento contestatório que pode diluir a força de estigmas que desqualificam esteticamente seu corpo negro entre amigos de sua rede social.

Assim, em nossa sociedade, em que impera uma visão das masculinidades negras como relacionadas ao desempenho sexual, sensualidade e tamanho do pênis, alinhar-se a essas reproduções discursivas pode destacar atributos de prestígio ligados à racialização das negritudes. Luan parece conhecer esses discursos e, estrategicamente, ancorado nessas mímicas (BHABHA, 2007), coloca em destaque a dimensão performativa da linguagem que perpassa a encenação de suas identificações de gênero/sexualidade e raça, construindo-se como um homem negro desejável e de desempenho sexual valorizado. Luan convoca posições estigmatizadas sobre seu corpo em contestação à prática de fiscalização de suas performances, que o posiciona como alguém que não se enquadra no padrão de beleza das branquitudes.

A seguir, destaca-se outro momento interacional em que discursos sobre gênero/sexualidade e raça estão em circulação compondo as performances de Luan, na negociação das assimetrias em jogo. O excerto abaixo foi retirado de uma interação de Luan no Facebook, no dia 19 de maio de 2011, e focalizará a interação entre Luan e Sávio. Sávio é estudante na mesma sala de aula de Luan e, de acordo com nossas observações etnográficas, posiciona-se como garoto branco e heterossexual. 
1 Post de Luan Final de tarde hora de comer um misto quente e tomar bons drinks,

2

3 Carla

4 Sávio

5

6 Rocha

7 Marcela

8 Luan

9

10

11 Maria

12 Sabrina
[10 curtir]

que que isso amiga tamaravilhosa ; k kkkkkkk [1 curtir]

negrinha, fala a verdade você vai é beber seu pão com água,

que acabou seu expediente na senzala

kkkkkkkkkkk

só porque sou preto, bjs :(

pode falar nem ligo. Com todo prazer sou NEGRO na senzala.

eu sei que vc ve ve quer...

depois disso se quiser te deleto do meu face, sem preconceitos Savio

hauhuahuahua b-)

porra se isso é tá na pior, o que é ta bem ;)

Na primeira linha do excerto, Luan entextualiza um vídeo de Luisa Marilac ${ }^{12}$, uma mulher trans que se identifica como travesti. Nesse post, Luan descontextualiza o vídeo viral ${ }^{13}$ de Luisa Marilac e o recontextualiza em seu texto, adaptando aos propósitos de participação nesse evento conversacional local. Esse vídeo é recuperado por meio da citação direta "bons drinks" (1.1), que aponta para um fragmento da fala de Luisa no referido vídeo. Luan recontextualiza essa fala como se fossem palavras dele e um interlocutor desavisado não conseguiria distinguir a voz de Luan da voz de Luisa Marilac. Nessa interação, a replicação da fala de Luisa Marilac será analisada quanto ao modo como Luan constrói suas performances de gênero, sexualidade e raça, através do comentário de Sávio.

Sávio (1.4) inicia sua postagem com o emprego do termo "negrinha", que adiciona outros sentidos às performances de Luan. O termo, entextualizado no diminutivo, é sugestivo de um footing irônico e depreciativo de Sávio com relação às performances de Luan e sinaliza negociação das relações de poder não ditas nessa interação social. $O$ não dito desta relação é a divisão que o ato de nomear cria entre Luan e esse interlocutor. Ao posicionar Luan por meio dessa referência, Sávio faz uso de signos com alto grau de estabilidade em nossa sociedade, que contribuem na construção das performances de Luan como negro e afeminado e na construção de suas próprias performances como um

\footnotetext{
${ }^{12}$ Referimos a um vídeo postado no Youtube, criado e compartilhado por Luisa Marilac. Nesse vídeo ela fala de sua vida na Europa, onde foi trabalhar como profissional do sexo. Ela aparece em uma piscina somente de biquíni, segurando uma taça e dizendo: "nesse verão resolvi fazer algo de diferente. Decidi ficar na minha casa, na minha piscina, tomando os meus bons drinks e curtindo esse verão maravilhoso da Europa, da Espanha e dividindo com vocês esses momentos meus". Este vídeo foi postado no dia 29 de junho de 2010 e tem 59seg. de duração. O material pode ser acessado na página do Youtube: http://www.youtube.com/watch?v=ikzC29rV75A.

${ }_{13}$ Os vídeos virais adquirem um alto poder de circulação na Internet, alcançando grande popularidade, configurando-se como um fenômeno de Internet típico da Web 2.0 (VARIS; BLOMMAERT, 2014).
} 
jovem branco e heterossexual. A referência "negrinha" realiza, portanto, um ato performativo institucionalizado e efetiva um outro hegemônico (Sávio) e um outro não hegemônico (Luan) na interação.

Além disso, através dos pares oracionais "fala a verdade" e "você vai é beber seu pão com água" (1.4), Sávio efetua uma avaliação das performances de Luan, exigindo (1) que o jovem diga a verdade sobre sua raça e assertivamente (2) referindo-se à história de sofrimento e escravidão dos negros no Brasil como a verdade de Luan. Esse alinhamento avaliativo é construído pelos itens lexicais "negrinha", "pão com água" e "senzala" e faz circular roteiros socioculturais estigmatizados, com base em uma suposta origem racial e que posicionam Luan como alguém que realiza trabalhos pesados e sofre.

Em resposta às postagens de Sávio, na linha 8 , Luan projeta um footing de assertividade "com todo prazer sou NEGRO da senzala" (1. 8). Os termos "NEGRO", em caixa alta, indicando timbre de voz mais alto, juntamente com "senzala" assinalam com cores fortes a dimensão performativa da raça de Luan e indicam um footing reflexivo e contestatório. Luan recontextualiza os signos estigmatizados que povoam os comentários de seu amigo, mas ao invés de atribuir às suas performances de raça uma inferiorização, reivindica valorização por intermédio da enunciação "com todo prazer" (1.8). Ainda, ao iniciar seu post com "pode falar nem ligo" (1.8), Luan projeta um footing de pessoa nãovitimizada com relação às possíveis práticas depreciativas desse amigo. Ao que parece, esse alinhamento constrói uma performance contestatória quanto a posicionamentos vitimizados.

Ademais, na entextualização da letra de Funk ${ }^{\mathbf{1 4}}$ "eu sei que vc vc vc quer" (1. 9), Luan erotiza suas performances de raça e propõe uma performance de sexualidade homoerótica para si e para Sávio. Com apoio da voz da Mulher Melão, ele cria uma associação entre o alinhamento provocador de Sávio e identificações de sexualidades homoeróticas, sugerindo um suposto desejo sexual de Sávio por Luan. Estrategicamente, Luan erotiza suas performances encenando supostas relações sexuais entre ele e Sávio. Nessa troca interacional, Luan deslegitima a vigilância de Sávio, ao colocar em xeque suas supostas performances de gênero/sexualidade heteronormativas. Esse alinhamento pode ser avaliado como uma ação de resistência, ao deslocar o olhar das diferenças, desestabilizando a autoridade desse outro hegemônico, que fala de um lugar aparentemente heteronormativo. Isso porque é conhecimento êmico entre participantes do Facebook que as interações naquele espaço estão abertas a avaliações e comentários de subjetividades distintas, com atores diversos. É lugar em que performances do contexto íntimo e privado podem entrar no jogo das avaliações coletivas e representar um risco às identificações heteronormativas das masculinidades fora daquele espaço, nesse caso, entre outros amigos de Sávio.

Assim, como parte do embate na construção de suas performances, nessa rede social, Luan renegocia significados de gênero, sexualidade e raça que circulam com base em discursos estereotípicos das identificações sociais. Luan novamente mostra conhecer o jogo interacional das relações saber-poder que constrói identificações rígidas a sua vida

\footnotetext{
14 "Você Quer?" (também conhecida como Você, Você, Você, Você, Você, Você, Você Quer?) é uma canção da funkeira brasileira Mulher Melão.
} 
corpórea. Ele se engaja em performances que produzem o efeito de identificações específicas: garoto negro, da senzala, de práticas sensuais e homoeróticas, recontextualizando aspectos das intersubjetividades racializadas e sexualizadas no nível sócio-histórico (da história de repetição de signos estigmatizados). Em um nível micro, Luan utiliza tais identificações a seu favor, em contestação aos footings projetados por Sávio. Tal combinação evidencia novamente o jogo da performatividade que perpassa a encenação das identificações sociais de Luan. Assim, ao construir-se como um jovem negro, de identificações homoeróticas e desejado por Sávio, Luan contesta as práticas homofóbicas e racistas interpretadas aqui como performances de masculinidades de Sávio.

\section{CONSIDERAÇÕES FINAIS}

Acreditamos que este artigo evidencia aspectos relevantes envolvidos na produção, circulação e interpretação de discursos referentes ao gênero, à sexualidade e à raça na contemporaneidade. As intensificadas formas de fluxo na Web 2.0 colocam em contato diferentes recursos culturais e pessoas, dando visibilidade à vida silenciosa das práticas discursivas. No caso das interações analisadas, a primeira cena coloca em destaque como as performances de Luan são constrangidas por uma matriz racial hegemônica que desqualificam esteticamente seu corpo negro. Na segunda cena, as performances de gênero/sexualidade e raça de Luan são constrangidas por uma matriz heteronormativa, por meio de discursos racistas e homofóbicos que povoam o comentário de seu amigo Sávio. Na interação com esses discursos, lutas performativas ocorreram no jogo das relações de força entre Luan e seus amigos Moreira e Sávio. Estrategicamente, ao contestar os lugares privilegiados nos quais seus amigos se localizam, Luan recupera signos cristalizados de raça e constrói-se como um garoto negro sensual e de identificações homoeróticas. Tais embates mostraram como suas entextualizações discursivas são utilizadas produtiva e agentivamente a serviço de uma micropolítica de destruição das posições hegemônicas produzidas por esses amigos.

Os discursos estereotipados, que configuram a experiência de pertencimento de Luan a grupos sociais inferiorizados, são aqui desmontados e desmantelados, possibilitando entender como, no mundo da Web 2.0, as práticas de construção de significados sobre o corpo, o gênero, a sexualidade e a raça, entre outros discursos solidificados, estão cada vez mais sujeitos ao debate público e a vozes e discursos dissonantes. Especialmente, no caso de Luan, compreende-se que ele pôde, em suas interações on-line, estrategicamente ensaiar outros significados sobre quem poderia ser, abrindo espaço para o exercício de novas formas de vida. Entendemos que essa é uma demanda crucial em um mundo de tamanhos questionamentos sobre fundamentalismos e essencialismos raivosos e, muitas vezes, beligerantes, que almejam extirpar a vida alteritária.

O caminho teórico-analítico apontando, neste artigo, permitiu também a observação da interseccionalidade de identificações de raça, gênero e sexualidade. Pôde-se observar que as identificações de raça estão em construção conjunta com as performances de gênero/sexualidade de Luan, uma vez que discursos raciais mostraram-se poderosos na 
negociação de seus relacionamentos afetivo-sexuais. Esperamos que este trabalho possa dialogar com outros estudos etnográficos (por exemplo, MELO; MOITA LOPES, 2014), apresentando diferentes aspectos das sociabilidades contemporâneas, principalmente no que tange à experiência de construção das identificações na Web 2.0, um lugar fundamental de enfrentamento com outridades.

\section{REFERÊNCIAS}

AGHA, A. Language and social relations. Cambridge, Cambridge University Press, 2007.

ANZALDÚA, G. To(o) queer the writer: loca, escrita y chicana. In: B. WARLAND (ed.). Versions: writing by dykes, queers and lesbians. Vancouver: Press Gang, 1991. p. 249- 263.

AUSTIN, J.L. How to do things with words. Oxford: Claredon Press, 1962.

AUSTIN, J.L. Quando dizer é fazer: palavras e ação. Trad. Danilo Marcondes De Souza Filho. Porto Alegre: Artes Médicas, 1962/1990.

BARNARD, I. Queer race: cultural interventions in the racial politics of queer theory. Nova York: Peter Lang, 2004.

BAUMAN, R.; BRIGGS, C. Poetics and performance as critical perspectives on language and social life. Annual Review of Anthropology, v.19, p. 59-88, 1990.

BAUMAN, Z. 44 Cartas do mundo líquido moderno. Rio de Janeiro: Zahar, 2011.

BHABHA, H. O local da cultura. Trad. Myriam Ávila, Eliana Lourenço, Gláucia Renate. Belo Horizonte: Ed. UFMG, 1994/2007.

BIAL, H. The performance studies reader. London: Routledge, 2003.

BLOMMAERT, J. Discourse. Cambridge: Cambridge University Press, 2005.

Sociolinguistic scales. Working papers in urban language \& literacies, v. 37, p. 1-15, 2006.

BLOMMAERT, J; RAMPTON, B. Language and superdiversity: a position paper. Working papers in urban language \& literacies, v.70, n.14, p. 1-22, 2011.

BLOMMAERT, J; WESTINEN, E.; LEPPANEN, S. Further notes on sociolinguistic scales. Tilburg papers in culture studies, v.89, p. 1-11, 2014.

BUTLER, J. Bodies that matter: on the discursive limits of 'sex'. Nova York e Londres: Routledge, 1993. Problemas de gênero: feminismo e a subversão da identidade. Tradução de Renato Aguiar. Rio de Janeiro; Civilização Brasileira, 1990/2003. Undoing gender. Nova York, Routledge, 2004a.

Performative acts and gender constitution: An essay in phenomenology and feminist theory. In: BIAL, H. (Org). The performance studies reader. Nova Iorque: Routledge, 2004b. p. 154-166.

COLLINS, J.; SLEMBROUCK, S. Goffman \& globalization: Participation frames and the spatial \& temporal scaling of migration-connected multilingualism. Working paper in urban language \& literacies, v. 46 , n. 3, p. 1-24, 2007.

COLLINS, J. Indexicalities of language contact in an era of globalization: engaging with John Gumperz's legacy. Text \& talk, v. 31, n. 4, p. 407- 428, 2011.

CONNELL, R.W.; MESSERSCHMIDT, J. W. Masculinidade Hegemônica: repensando o conceito. Revista Estudos Feministas, v. 21, n. 1, p. 241-282, jan./abr. 2013.

COSTA DE PAULA, R. “Não quero ser branca não. Só quero um cabelo bom, cabelo bonito!” Performances de corpos/cabelos de adolescentes negras em práticas informais de letramento. Tese ( Doutorado em Linguística Aplicada) - Programa de Pós-Graduação em Linguística Aplicada, Universidade Estadual de Campinas, Campinas, 2010.

COUPLAND, N. Style: language variation and identity. New York: Cambridge University Press, 2007. D‘ADESKY, J. Pluralismo étnico e multiculturalismo: racismos e anti-racismos no Brasil. Rio de Janeiro: Pallas, 2001.

DERRIDA, J. Limited Inc. Trad. de WEBER, S. Evanston: Northwestern University Press, 1972/1988.

GUIMARÃES, Thayse Figueira; LOPES, Luiz Paulo da Moita. Entextualizações estratégicas: performances sensualizadas de raça em práticas discursivas na Web 2.0. Linguagem em (Dis)curso - LemD, Tubarão, SC, v. 16, n. 2, p. 289-307, maio/ago. 2016. 
ERICKSON, F. What makes school ethnography 'ethnographic'? Anthropology and education. Quartely, v.15, p. 51-66, 1984.

GOFFMAN, E. Frame analysis: an essay on the organization of experience. New York, Harper \& Row, 1974.

Forms of Talk. Filadélfia: University of Pennsylvania Press, 1981.

GUERREIRO, G. Terceira diáspora, culturas negras no mundo atlântico. Salvador: Corrupio, 2010.

GUIMARÃES, A. S. Como trabalhar com "raça" em sociologia. Educação e Pesquisa, v. 29, n. 1, p. 93 107, 2003.

GUIMARAES, T. F. Embates entre performances corpóreo-discursivas em trajetórias textuais: uma etnografia multissituada. Tese (Doutorado em Linguística Aplicada) - Programa Interdisciplinar de PósGraduação em Linguística Aplicada, Universidade Federal do Rio de Janeiro, Rio de Janeiro, 2014.

GUMPERZ, J. Convenções de contextualização. In: RIBEIRO, B.T.; GARCEZ, P. M. (Orgs.)

Sociolinguística interacional: antropologia, linguística e sociologia em analise do discurso. Porto Alegre; Edições Loyola, 1982/2002. p. 98-119.

HINE, C. Virtual ethnography. London: Sage Publications, 2000.

KERBRAT-ORECCHIONI, C. La conversation. Paris, Seuil, 1996.

LANKSHEAR, C.; KNOBEL, M. (orgs.) Digital literacies. Concepts, policies and practices. Nova York: Peter Lang, 2008.

LOXLEY, J. Performativity. Londres, Routledge, 2007.

MARCONDES, D. A filosofia da linguagem de J. L. Austin. In: AUSTIN, J. L. Quando dizer é fazer. Palavras e ação. Porto Alegre: Artes Médicas, 1990. p 7-17.

MELO, G. C.V.; MOITA LOPES, L.P. Ordens de indexicalidade mobilizadas nas performances discursivas de um garoto de programa: ser negro e homoerótico. Linguagem em (Dis) curso, v. 14, n. 3, p. 653-685, 2014.

MISKOLCI, R. A Teoria queer e a sociologia: o desafio de uma analítica da normalização. Sociologias, v.11, n. 21, p. 150-18, 2009.

MOITA LOPES, L.P. Uma Linguística aplicada mestiça e ideológica: interrogando o como linguista aplicado. In: MOITA LOPES, L.P. (Org.) Por uma linguística aplicada indisciplinar. São Paulo, Parábola, 2006/2014. p. 13-42.

OLIVEIRA, L. Entre discursos, jeitos e gestos: performance de gênero e sexualidade no mercado erótico de travestis e cross-dressers. In: MOITA LOPES, L. P.; BASTOS, L. C. (Orgs.). Para além da identidade: fluxos, movimentos e trânsitos. Belo Horizonte: Ed. UFMG, 2010. p. 235-259.

PENNYCOOK, A. Performance and performativity. In PENNYCOOK, A. Global englishes and transcultural flows. London: Routledge, 2007. p. 58 - 77.

PRECIADO, B. Entrevista com Beatriz Preciado. Revista poiésis, v. 15, p. 47-71, 2010.

RIBEIRO, B.T.; GARCEZ, P. M. Introdução ao capítulo "Footing". In: RIBEIRO, B.T.; GARCEZ, P.M. (Org.). Sociolinguística interacional: antropologia, linguística e sociologia em analise do discurso. Porto Alegre: Edições Loyola, 2002. p. 107-148.

SCHIFFRIN, D. Approaches to discourse. Cambridge, Mass, Blackwell, 1994.

SILVERSTEIN, M. Indexical order and dialectics of sociolinguistic life. Language \& communication, $\mathrm{v}$. 23, n. 3-4, p. 193-229, 2003.

SILVERSTEIN, M.; URBAN, G. (Eds.) Natural histories of discourse. Chicago: The University of Chicago Press, 1996.

SOMMERVILLE, S. B. Queering the color line: race and the inventions of homosexuality in American culture. Durham: Duke University Press, 2000.

SULliVAN, N. A Critical introduction to queer theory. Nova Iorque: New York University Press, 2003. TRESTER, A. M. Framing entextualization in improv: Intertextuality as an interactional resource. Language in society, v. 41, p. 237-258, 2012.

VARIS, P; BLOMMAERT, J. Conviviality and collectives on social media: Virality, memes, and new social structures. Tilburg Papers in Culture Studies, Tilburg University, n.108, p. 1-21, 2014.

WITTEL, A. Ethnography on the move: From field to net to Internet. Forum: Qualitative social research (FQS), v.1, n.1, p. 21-41, 2000.

GUIMARÃES, Thayse Figueira; LOPES, Luiz Paulo da Moita. Entextualizações estratégicas: performances sensualizadas de raça em práticas discursivas na Web 2.0. Linguagem em (Dis)curso - LemD, Tubarão, SC, v. 16, n. 2, p. 289-307, maio/ago. 2016. 
WORTHAM, S. Narratives in action. New York: Teacher College Press, 2001.

WOYDACK, J; RAMPTON, B. Text trajectories in a multilingual call centre: The linguistic ethnography of a calling script. Working papers in urban language \& literacies, v.147, p. 1-24, 2015.

\title{
Recebido em: 14/10/15. Aprovado em 04/05/16.
}

Title: Strategic entextualization: sensualized performances of race in discursive practices on the web 2.0

\begin{abstract}
Authors: Thayse Figueira Guimarães; Luiz Paulo da Moita Lopes
Abstract: This paper analyzes the discursive practices of Luan, a young black man of homoerotic identifications, interacting on the Web 2,0. The data was generated in an ethnographic investigation on the interactional network: the Facebook. Entextualization concepts and performance are privileged considering the observation processes of circulation and destabilization of crystallized discourses of race in the construction of identifications of Luan as black, sexy boy. We advocate these concepts are the key to comprehend how that discourses are strategically used by the young man when he build his performances on interactions with friends from this social network. The analyses show that race identifications are constantly intermingled with performances of gender and sexuality, and agency strategies emerge amidst a profusion of normative meanings.
\end{abstract}

Keywords: Identity performance. Entextualization. Agency.

Título: Entextualizaciones estratégicas: actuaciones sensuales de raza en prácticas discursivas en la web 2.0

Authors: Thayse Figueira Guimarães; Luiz Paulo da Moita Lopes

Resumen: Este artículo focaliza las prácticas discursivas de Luan, un joven negro y de identificaciones homo eróticas en interacciones en la Web 2.0. Los datos fueron generados en una investigación etnográfica, en el contexto de interacción de la red social Facebook. Las nociones de entextualización y de performances son privilegiadas para dar cuenta de la observación de los procesos de circulación y desestabilización de discursos cristalizados de raza, en la construcción de las identificaciones de Luan como joven hombre negro y sensual. Se defiende que tales nociones son la clave de lectura para la comprensión de como tales discursos son estratégicamente utilizados por el joven, al construir sus performances en las interacciones con amigos de esa red social. Los análisis apuntan que identificaciones de raza son permeadas por marcas de género/sexualidad y que estrategias de agenciar emergen en medio a una profusión de significados normativos.

Palabras-clave: Performance de identidad. Entextualización. Estrategias de agenciar.

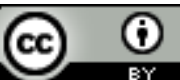

Este texto está licenciado com uma Licença Creative Commons Atribuição 4.0 Internacional. 